\title{
Effect of Physical Exercise on Serum Electrolytes, Urea and Creatinine in Undergraduate Footballers in Anambra State, Nigeria
}

\author{
Michael Chinedu Olisah ${ }^{1}$ and Dim Catherine Nicholate \\ ${ }^{1}$ Deparment of Medical Biochemistry and Chemical Pathology, Chukwuemeka Odumegwu Ojukwu University, Uli. \\ ${ }^{2}$ Deparment of Physiology, Faculty of Basic Medical Science, Chukwuemeka Odumegwu Ojukwu University, Uli
}

*Correspondence: olisemike2007@yahoo.com; mobile no: +234(0)8038884404

\begin{abstract}
Background: Prolonged exercise leads to progressive water and electrolyte loss from the body as sweat is secreted to promote heat loss. The rate of sweating depends on many factors and is increased in proportion to the work rate and the environmental temperature and humidity. Prolong exercise could lead to alteration in electrolyte concentrations and this could lead to deleterious effect in the body. Aim: To determine the effect of Physical Exercise on Serum Electrolytes Urea and Creatinine in undergraduate footballers in Anambra State. Method: Six football teams comprising of 11 players each was grouped into 3 sets. Each set containing 22 players were allowed to play football for at least 2 hours with a 15 minutes break interval. They were allowed to take only $250 \mathrm{mls}$ water during this exercising period. Blood samples were collected from all the subjects prior to the exercise from anticubital veins with the subjects in sitting position. Post-Exercise blood Samples were collected within 5 minutes after and $2 \mathrm{hrs}$ after the exercise. The blood samples were also analyzed for serum electrolytes, urea and creatinine. Blood sample for calcium was collected after removing the tourniquet for 2 minutes. The serum concentrations of sodium, potassium, bicarbonate, chloride and calcium were estimated using ion selective electrodes while urea and creatinine were estimated using standard colorimetric methods. Results: There was no significant difference in mean concentrations of serum electrolytes $\left(\mathrm{Na}+, \mathrm{K}+, \mathrm{Cl}_{-}\right.$and $\mathrm{HCO}_{-}$) profile levels in pre exercising subjects when compared with the post exercising period. $(\mathrm{P}>0.05)$. However, the mean levels of $\mathrm{Ca}+$ increased significantly in post exercise period when compared with the pre exercising condition $(\mathrm{P}<0.05)$. The findings of this work suggest that short duration of exercise does not alter significantly the serum electrolytes.
\end{abstract}

\section{Article History}

Received: 04 June 2021

Accepted: 05 August 2021

Published: 09 Oct. 2021

\section{Scan QR code to view*}
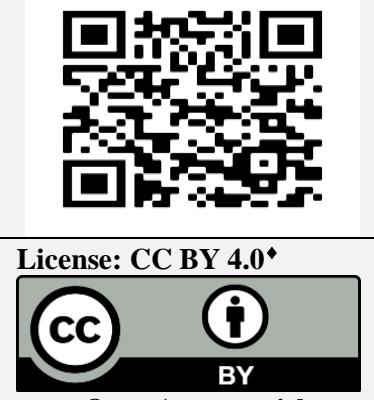

Open Access article

Keywords: Physical exercise, Serum Electrolytes, footballers.

How to cite this paper: Olisah, M. C., \& Nicholate, D. C. (2021). Effect of Physical Exercise on Serum Electrolytes Urea and Creatinine in Undergraduate Footballers in Anambra State, Nigeria. IPS Interdisciplinary Journal of Biological Sciences, 1(1), 8-10. https://doi.org/10.54117/iijbs.v1i1.2

\section{Introduction}

Exercise can be defined as physical activity that is planned, structured, and repetitive for the purpose of conditioning the body. It is any bodily activity that enhances or maintains physical fitness and overall health and wellness. (Kylasov and Gavrov, 2011). It consists of cardiovascular conditioning, strength, resistance training, and flexibility. It is also essential for improving overall health, maintaining fitness, and helping to prevent the development of obesity, hypertension, and cardiovascular disease. It improves mental health, helps prevent depression and helps to promote or maintain positive self-esteem (Kawano et al., 2009; Malatesta et al., 2009). Physical activity plays an active role in the prevention of noncommunicable diseases, such as coronary heart disease, diabetes mellitus type II, dyslipidemia, obesity, breast and colon cancers in addition to the prevention of dementia, depression, and premature death (Abby et al., 2017). During physical exertion, the people experience reversible, sometimes irreversible alterations in various homeostatic functions.

Electrolytes are the positively and negatively charge molecules called ions that are found within the cells and extracellular fluid compartment of blood
(Henry et al., 2001). They play a role in conducting nervous impulses, contracting muscles, keeping the body hydrated and regulating body's $\mathrm{pH}$ levels. Disturbances in electrolytes may have a harmful effect on health and can even be fatal in rare cases As a result, long periods of exercise or activity, particularly in the heat, can cause significant electrolyte loss.

However, certain populations, such as endurance athletes who are exercising for more than two hours or those who exercise in extreme heat, may want to consider drinking electrolyte-enriched sports drinks to replace their losses. Typically, the most important factor in regard to electrolyte loss during exercise is the amount of sweat lost. As individual sweats during exercise, not only do they lose fluid, but also lose many of the electrolytes needed to keep the body hydrated and balanced. In the last decade, there has been increasing interest in the idea that individuals engaged in exercises may have an increased need for several of the essential minerals. This idea has resulted in the widespread perception that mineral supplements may be advantageous for this group of population. The concept is based on two basic perceptions: 
(i) Individuals engaged in strenuous exercise have a higher requirement for some minerals compared to sedentary individuals due to increased rates of urinary and sweat losses

(ii) Inadequate intake of some essential minerals may lead to the development of some disease states.

Although a significant number of athletes and professionals in the sports medicine field believe in effects of mineral supplements, there are remarkably few data supporting a positive effect of dietary mineral supplementation on athletic performance. However, this research is targeted to determine if strenuous exercise does influence loss of several minerals and to determine if the loss of those minerals is significant enough to cause deleterious effect.

\section{Materials and Methods}

\section{Subjects}

This study was conducted at the training field of Chukwuemeka Odumegwu Ojukwu University, Uli. This was done during the weekend physical exercise activities done by the students of the university. Sixty (60) subjects were recruited, randomly from footballers.

\section{Sample Size}

Sample size calculation was done using $95 \%$ confidence interval, 0.05 precision and prevalence rate. There seem to be no data available as regards the proportion of Anambra State residents that participate in various forms of physical exercise, but, high physical activity levels assessed in Ibadan, Western Nigeria, reported 3.2\% (Odunaiya et al., 2010).

The formula for sample size when population is more than 1000 is: $\mathrm{n}=$ $\mathrm{Z} 2 \mathrm{PQ} / \mathrm{d} 2$

$\mathrm{n}=\mathrm{Z} 2 \mathrm{PQ} / \mathrm{d} 2$

Where:

$\mathrm{n}=$ minimum sample size, is 1.96 ,

$\mathrm{Z}=$ standard normal deviation at $95 \%$ confidence interval which

$\mathrm{d}=$ degree of precision (taken as 0.05 ),

$\mathrm{P}=$ proportion of the target population (estimated at $3.2 \%$ which is $3.2 / 100=0.032$ ),

$\mathrm{Q}=$ alternate proportion $(1-\mathrm{P})$ which is $1-0.032=0.968$

$\mathrm{n}=(1.96) 2(0.032)(0.968)=48$

$$
(0.05) 2
$$

\section{Inclusion Criteria}

(i) Subjects were made up of only males of between 18-30 years.

(ii) Subjects must not have participated in any strenuous exercise for at least one month.

(iii) Subjects must not have any history of medical illness.

(iv) Subjects must not be recently on medicinal drug use.

Recruitment of subjects: After verbal consent, detailed personal, and medical questionnaire was completed by the foothballers through personal interview.

Ethical Approval: Ethical approval was gotten from the research Ethics committee of faculty of Basic Medical Sciences.

\section{Pre exercise, exercise and post exercise period}

Six football teams comprising of 11 players each was group into 3 sets. Each set containing 22 players were allowed to play for at least 2 hours with a 15 minutes break interval. They were allowed to take only $250 \mathrm{mls}$ water during this exercising period.

\section{Pre-Exercise Blood Samples:}

Blood samples were collected from all the subjects prior to the exercise from anticubital veins with the subjects in sitting position. Post-Exercise blood Samples were collected within 5 minutes after and $2 \mathrm{hrs}$ after the exercise. The blood samples were also analyzed for serum electrolytes, urea and creatinine. Blood sample for calcium was collected after removing the tourniquet for 2 minutes. All blood samples were stored in a sealed containers tubes and were later centrifuged at 4000 revolution per minute (RPM) for 10 minutes and the serum of each sample was extracted into fresh plain bottle for analysis, while those not immediately analyzed were stored at -20 degree celsius until analysis few days later. The blood samples were analyzed for serum electrolytes, urea and creatinine.

\section{Methods for Analysis}

Electrolyte determination using ion selective electrode

Electrolytes were determined using ion selective electrode by Bard and Faulkner (2000).

Estimation of Serum Sodium estimation was done using sodium reagent set by Teco Diagnostics.

Estimation of Serum Potassium: Potassium estimation was done using Turbidimetric test-TPB method of the test kit by Quimica Clinical Aplicada S.A.

Determination of Serum Bicarbonate by modified method of Von-Slyke Determination of Urea Level (Roche Diagnostics, USA).

Blood urea was determined by the method described by Kassirer, (1971). Determination of Creatinine Level (Roche Diagnostics, USA).

Serum creatinine was estimated by Jaffe's method as described by Laron, (1972).

\section{Statistical Analysis}

Data was statistically analyzed using Statistical Package for the Social Sciences (SPSS) for windows version 20.0 software. All data were expressed as Mean \pm Standard Deviation (SD). Statistical analysis of before exercise, two weeks after exercise and four weeks after exercise data was performed by Analysis of Variance (ANOVA) while multiple comparisons were done using Post Hoc test. Significance was fixed at P $<$ 0.05 .

\section{Results and Discussion}

In this study (Table 1), there was no significant difference in mean concentrations of serum electrolytes $\left(\mathrm{Na}+, \mathrm{K}+, \mathrm{Cl}^{-}\right.$and $\left.\mathrm{HCO}_{3}{ }^{-}\right)$profile levels in exercising subjects when compared with the post exercising group. ( $\mathrm{P}>0.05)$. However, the mean levels of $\mathrm{Ca}+$ increased significantly in exposed group when compared with the control group $(\mathrm{P}<0.05)$. Prolonged exercise leads to a progressive water and electrolyte loss from the body as sweat is secreted to promote heat loss.

From our findings, exercising footballers have a reduction in serum sodium concentration $2 \mathrm{hs}$ after exercising compared with pre exercise condition. The serum sodium however, normalized 2 hours after the exercise. The reduction in serum sodium level during exercise can be attributed to the loss of sodium in sweat during exercise. This is in accordance with the finding of Sanders et al. (2001), and Ugwuja et al (2014). Though, there is reduction in serum sodium, the reduction was not sufficient to cause hyponatreamia. Speedy et al. (2001) and Noakes (2002), have observed cases of hyponatraemia during endurance exercise in heat. Also, $\mathrm{Ri}$ (2006) highlighted the importance of sodium in fluid homeostasis and advised that persons engaging in long distance exercise should drink as much fluid as possible to prevent dehydration and hyponatraemia. Also observed in our study is a significant reduction in serum chloride. This is however not surprising as both sodium and chloride is the main constituent of sweat in form of salt. Potassium is mostly an intracellular mineral which, interacts with sodium via action potentials in conduction of nerve impulses. Our findings showed a reduction in serum potassium and this could be due to the fact that the exercise duration with sweating and lasted for forty five minutes. It is also expected that if the exercise is prolonged without taking any fluid with increased breakdown of glycogen to supply energy for the body the muscle cells will be depleted of potassium resulting in increase in serum potassium concentration.

Similarly serum bicarbonate concentration changes in our research showed a little decrease. This is not far from the fact that during the exercise period, there may be exercise induced tachycardia. This is also in consonance with Rojas et al. (2006). Serum potassium is not left out in the alteration in serum electrolyte changes associated with exercise. 
Table 1: Mean serum levels of serum electrolytes, urea and creatinine

\begin{tabular}{|c|c|c|c|c|c|c|c|}
\hline Groups & $\mathrm{Na}(\mathrm{mmol} / \mathrm{L})$ & $\mathbf{K}^{+}(\mathbf{m m o l} / \mathbf{L})$ & $\mathrm{Cl}^{-}(\mathrm{mmol} / \mathrm{L})$ & $\mathrm{HCO}_{3^{-}}(\mathrm{mmol} / \mathrm{L})$ & Urea $(\mathrm{mmol} / \mathrm{L}$ & Creati $(\mu \mathrm{mol} / \mathrm{L})$ & $\mathrm{Ca}^{2+}(\mathrm{mmol} / \mathrm{L})$ \\
\hline $\begin{array}{l}\text { Pre exercise } \\
\text { (A) }\end{array}$ & $144.21 \pm 2.88$ & $3.27 \pm 0.30$ & $102.37 \pm 2.58$ & $23.28 \pm 1.45$ & $3.03 \pm 0.69$ & $74.50 \pm 10.09$ & $3.8 \pm 0.41$ \\
\hline $\begin{array}{l}5 \text { mins after } \\
\text { exercise (B) }\end{array}$ & $140.84 \pm 1.53$ & $3.15 \pm 0.431$ & $100.1 \pm 21.87$ & $22.22 \pm 1.80$ & $4.10 \pm 0.74$ & $75.15 \pm 7.20$ & $4.5 . \pm 0.52$ \\
\hline $\begin{array}{l}\text { 2hrs after } \\
\text { exercise (C) }\end{array}$ & $142.89 \pm 2.02$ & $3.45 \pm 0.23$ & $101.1 \pm 3.67$ & $21.72 \pm 1.60$ & $4.53 \pm 0.84$ & $78.12 \pm 9.20$ & $3.9 \pm 0.31$ \\
\hline$P$ value & 1.01 & 0.930 & 0.74 & 0.921 & 0.16 & 0.13 & 0.01 \\
\hline \multicolumn{8}{|l|}{ POST Hoc } \\
\hline $\mathbf{A} / \mathbf{B}$ & 1.00 & 0.78 & 1.00 & 0.67 & 0.83 & 0.73 & 0.04 \\
\hline $\mathbf{A} / \mathbf{C}$ & 0.98 & 0.97 & 0.94 & 0.83 & 0.83 & 0.96 & 0.01 \\
\hline $\mathrm{B} / \mathrm{C}$ & 1.00 & 1.00 & 1.00 & 0.73 & 0.34 & 0.82 & 0.09 \\
\hline
\end{tabular}

\section{* Significant at $\mathbf{p}<0.05$}

\section{Conclusion}

Alteration in serum electrolyte is always a serious problem when their concentration is either too high or low and can cause sudden death. It is therefore very important that those embarking in serious physical exercise especially prolonged one should take as much fluid as possible especially water and electrolyte alteration.

\section{References}

Brad A.J., Larry R.F. (2001). Electrochemical Methods: Fundamentals and Applications, 2nd Edition 864 Pages.

Carl L. Keen, Departments of Nutrition and Internal Medicine, University of California, Davis, CA 95616-8669, (1989). Recommended Dietary Allowances, 10th ed. Report of the Subcommittee on the Tenth Edition of the RDAs, Food and Nutrition Board, Commission on Life Sciences. Washington, D.C.: National Academy Press.

Kassirer, J.P. (1971). Clinical Evaluation of Kidney Function Glomerular Function. New Engl Journal Med 1971; 285:385-389. https://doi.org/10.1056/NEJM197108122850706

Kylasov A, Gavrov S. Diversity of Sport: non-destructive evaluation. Paris: UNESCO:Encyclopedia of Life Support Systems; 2011. pp. 462-91. ISBN 978-5-89317-227-0

Noakes, T.D., Noman, R.J., and Buck, R.H. (1990). The Incidence of Hyponatraemia During Prolong Ultra-endurance Exercise. Medicine and Science in Sport and Exercise 22:165-70 https://doi.org/10.1249/00005768-199004000-00148

Noakes, T. (2002). Hyponatraemia in Distance Runners;Fluid and Sodium Balance During Exercise. Current Sports Medicine Representatives 1:197-207. https://doi.org/10.1249/00149619$\underline{\text { 200208000-00003 }}$

Odunaiya N.E, Ayodele, O.A, Oluwafemi, O. (2010). Physical Activity Levels of Senior Secondary School Students in Ibadan, Western Nigeria. The West Indian medical journal 59(5):529-34

Rojas, V.S., Struder, H.K., Wamann, B.V., Bloch, W. And Hollmann, W. (2006). Bicarbonate Reduces Prolectin Increase Induced by Exercise. Exhaustion.Medicine and Science in Sports and Exercise 38(4):675680. https://doi.org/10.1249/01.mss.0000210195.94952.50

Ri, S. (2006). Role of Sodium in Fluid Homeostasis with Exercise. Journal of the American College of Nutrition 25(3)231s-239s https://doi.org/10.1080/07315724.2006.10719572

Sanders, B., Noakes, T.D. and Dennis, S.C. (2001).Sodium Replacement and Fluid Shift During Prolong Exercise in Human.European Journal of Applied Physiology 84:419-425. https://doi.org/10.1007/s004210000371

Senay, L.C. (1968). Relationship of Evaporative Rates to Serum [Na+], $[\mathrm{K}+]$, and Osmolarity in Acute Heat Stress. Journal of Applied Physiology 25:149-152. https://doi.org/10.1152/jappl.1968.25.2.149

Speedy, D.B., Campbell, R. and Mullingan, G. (1997). Weight Change and Serum Sodium Concentration After an Ultraendurance Multi Sport Triathlan. Clinical Journal of Sports Medicine 7:100-103. https://doi.org/10.1097/00042752-199704000-00005

Ugwuja, S E, Obeagu E.I, Ochei K. C, Ogbu R. O, Agoha S. C. (2014). Effect of Physical Exercises on Serum Electrolyte. IOSR Journal of Dental and Medical Sciences .Vol 13: 9: PP 118-121 https://doi.org/10.9790/0853-1392118121

\footnotetext{
- Thank you for publishing with us.
} 